DOI: 10.17707/AgricultForest.63.1.31

\author{
Mohammad Reza Safari MOTLAGH, Saber MOHAMMADIAN ${ }^{1}$
}

\title{
IDENTIFICATION OF NON-PATHOGENIC FUNGI OF RICE AND THE EVALUATION OF THEIR EFFECT ON BIOLOGICAL CONTROL OF BIPOLARIS ORYZAE, THE CAUSAL AGENT OF RICE BROWN SPOT DISEASE IN VITRO
}

\begin{abstract}
SUMMARY
Rice brown spot disease is caused by Bipolaris oryzae is an important disease of rice in Iran and other parts of the world. In this research, 137 infected samples of rice were collected from paddy fields of Guilan province in Iran and 68 fungal isolates were isolated. PDA and WA media were used for isolation and identification of fungi. Morphological characteristics such as colony, conidia and conidiophores morphology were used for identification of these fungi. It was found that the isolated fungi belonged to Bipolaris oryzae, Alternaria tenuissima, Preussia sp., Fusarium verticillioides, Alternaria infectoria, Alternaria citri, Trichoderma harzianum and Trichoderma virens. Twenty isolates that didn't cause disease on rice or pathogenicity of them in rice was very low were selected for biocontrol studies and to do so, various methods were used. It was shown that seven isolates, T. harzianum, T. virens, A. tenuissima, Preussia sp., $F$. verticillioides, $A$. infectoria and $A$. citri, had the highest suppression percentage of mycelial growth of $B$. oryzae, respectively, in dual culture and culture filtrate methods. In volatile metabolites method, T. harzianum, T. virens, A. tenuissima, A. infectoria, A. citri, Preussia sp. and $F$. verticillioides, had the highest inhibition percentage of mycelial growth of $B$. oryzae, respectively. In hyperparasitism test, no coiling of Trichoderma spp. was observed around the hyphae of B. oryzae, however, Alternaria spp. penetrated into the mycelium of $B$. oryzae once they reached them and then, they tore the fungal mycelium and deformed it. Based on obtained results, T. harzianum was the most effective isolate in inhibiting the mycelial growth of $B$. oryzae. Analysis of variance and means comparison by least significant difference showed significant differences among the fungi used in vitro.
\end{abstract}

Keywords: antagonist, rice, biological control, Bipolaris spp., nonpathogenic fungi

\section{INTRODUCTION}

Rice brown spot disease is one of the most important diseases of rice whose symptoms may be displayed from nursery to farm (Safari Motlagh, 2000).

\footnotetext{
${ }^{1}$ Mohammad Reza Safari Motlagh, (corresponding author: ssafarimotlagh@yahoo.com), Department of Plant Pathology, Faculty of Agriculture, Rasht Branch, Islamic Azad University, Rasht, Guilan province, IRAN; Saber Mohammadian, Master of Microbiology, Department of Microbiology, Rasht Branch, Islamic Azad University, Rasht, IRAN

Notes: The authors declare that they have no conflicts of interest. Authorship Form signed online.
} 
The fungus creates small round brown spots on host seedlings which may completely encircle coleoptile deforming the primary and secondary leaves (Khodaparast and Sahragard, 2004). In extreme cases, the seedlings in nursery are burned and the spikes are hollowed and blackened in farm (Safari Motlagh, 2000). The disease is caused by Bipolaris spp. (Safari Motlagh, 2000). This genus includes numerous species which mostly attack wheat, rice, barley and other grains. Brown spot, caused by Bipolaris oryzae (Breda de Haan) Shoemaker, is one of the most important seed borne diseases of rice and is an economically important foliar disease (Ou, 1985). In 1942, an outbreak of the disease caused yield losses of $90 \%$ which resulted in famine in Bengal (Nazari et al., 2015) and was one of the major reasons for the death of 2 million people (Nazari et al., 2015). It causes seedling blight and damages the foliage and panicles of rice, particularly when rice is grown in nutritionally deficient or unfavorable soils (Nazari et al., 2015). Biological control of plant pathogens is a relatively slow process, it has long-running, cheap and environmentally-friendly effects and can be a good alternative for chemicals (Kazemzadeh Chekosari, 2003). Microorganisms which are suitable for the biological control of plant pathogens have been identified among fungi and bacteria (McSpadden Gardener and Fravel, 2002).

Elad et al. (1980) examined the impact of a Trichoderma harzianum isolate on Rhizoctonia solani and Sclerotium rolfsii and found that T. harzianum grew faster than $S$. rolfsii in culture medium and attacked its mycelium.

The biological control of $R$. solani in cotton has been reported by Trichoderma and Gliocladium in field and by Gliocladium virens in greenhouse (Howell, 1982; Lewis and Papavizas, 1991).

In an in vitro and greenhouse study on the effect of isolates of Trichoderma on Fusarium oxysporum f. sp. lycopersici pathogen, Niknejad and Sharifi Tehrani (1993) found that gaseous compounds and extra-cellular exudations of Trichoderma had significant impact on the inhibition of mycelial growth of the pathogen.

The role of chitinase produced by Stenotrophomonas maltophilia in biological control of Bipolaris sorokiniana in Festuca arundinacea was studied and it was cleared that this enzyme can be effective in biological control of $B$. sorokiniana (Zhang and Yuen, 2000).

Salehpour et al. (2005) studied biological control of B. sorokiniana, the causal agent of wheat root rot by isolates of Trichoderma and results showed that $T$. viride was the most effective species in reducing the severity of infection in plant.

Abdel-Fattah et al. (2007) investigated the antagonistic mechanisms of $T$. harzianum against $B$. oryzae. The in vitro antagonistic effect of $T$. harzianum was brought about by its growth on $B$. oryzae and also, $T$. harzianum antifungal metabolites suppressed the linear growth of $B$. oryzae.

In an in vitro study on antifungal activities of Pseudomonas fluorescens strains against Alternaria cajani, Curvularia lunata, Fusarium spp. and Bipolaris 
spp., it was revealed that all strains had good antagonistic effects against $A$. cajani and C. lunata (Srivastava and Shalini, 2008).

The antifungal activity of 86 isolates of Bacillus sp. was studied against Bipolaris sorokiniana as the causal agent of wheat brown spot and the isolate E64 was found to be the most effective (Carissimi et al., 2009).

The antagonistic potential of 135 local isolates of Trichoderma was, also, examined against Phytophthora palmivora, the causal agent of cocoa black pod, and the isolate T17 belonging to T. virens was found to be the most effective biocontrol agent hindering the mycelial growth of pathogen by over 97\% (Mpika et al., 2009)

In a study, the biocontrol effect of some actinomycete isolates obtained from different habitats of Manipur, India was examined on major rice pathogens including Curvularia oryzae, Pyricularia oryzae, Bipolaris oryzae and Fusarium oxysporum. LSCH-10C isolated from Loktak Lake was found to be a promising biocontrol agent (Ningthoujam et al., 2009).

In greenhouse and in vitro studies on the effect of 200 Trichoderma strains isolated from soil, plant debris and phyllosphere in paddy fields of Mazandaran province on Rhizoctonia solani, Naeimi et al. (2011) revealed that some strains belonging to $T$. harzianum, $T$. virens and $T$. atroviride controlled the disease agent effectively.

In a study on biological control of Bipolaris oryzae in India, it was found that Aspergillus niger, A. fumigatus, A. flavus, A. sulphureus, A. terreus, Penicillium chrysogenum, $P$. janthinellum, $T$. viride and $T$. harzianum significantly reduced growth of $B$. oryzae (Manimegalai et al., 2011).

Khalili et al. (2012) investigated the influence of local isolates of Trichoderma isolated from rice fields of the Guilan and Mazandaran provinces on controlling rice brown spot caused by B. oryzae in which 145 Trichoderma isolates belonging to $T$. atroviride, $T$. harzianum and $T$. virens were screened in greenhouse and in vitro to find the best species for effective biocontrol of $B$. oryzae. Two strains belonging to $T$. harzianum significantly controlled the disease and two strains belonging to $T$. atroviride improved seedling growth (Khalili et al., 2012).

In a study, biological control of B. oryzae by Pseudomonas synxantha and Bacillus sp. was studied and it was cleared that disease severity decreased in rice infected seeds treated with bacteria (Moura et al., 2014).

Soltani Nejad et al. (2014) investigated biological control of $B$. oryzae by isolates of Streptomyces sp. and it was found that G isolate had more antagonistic activity.

Rice brown spot disease which hollow the seeds and impose heavy losses on paddy fields are observed from the nurseries to the fields in Guilan province. Since the methods to control the disease including chemical and agronomical methods have shortages, a new approach must be looked for like the use of antagonistic fungi to counteract the disease. The general objective of the present 
study was to find fungus (fungi) in natural rice plant flora for in vitro suppression of Bipolaris oryzae, without causing disease on rice.

\section{MATERIAL AND METHODS \\ Collection and culture of fungal isolates}

Leaves with symptoms of the diseased rice were collected in Guilan province of Iran, then cut to appropriate sizes and transferred to the laboratory. Samples were surface sterilized with $0.5 \%$ sodium hypochlorite solution, washed by sterile distilled water and placed on potato dextrose agar in petri dishes. Then, petri dishes were incubated at $28^{\circ} \mathrm{C}$ in darkness or light on a 12 hours light/dark photoperiod for 6-15 days. Conidia were single-sporulated and then, monoconidial isolates of the recovered fungi were maintained on half-strength potato dextrose agar (PDA) slants in test tubes as stock cultures (Safari Motlagh, 2010).

\section{Study and identification of fungi}

Morphological studies were carried out on water agar (WA) medium. Cuts of colonies were placed onto PDA medium for 2-3 days. Then, section of colonies was transferred to WA medium for 7-30 days in incubator at $27^{\circ} \mathrm{C}$ and $12 \mathrm{~h}$ photoperiod. Afterwards, morphological observations were taken based on colony, conidium and conidiophore morphology and other morphological charactersitics (Ellis, 1971; Sivanesan, 1987; Gams and Bissett, 1998; Arenal et al., 2004; Arenal et al., 2007; Cain, 1961; Leslie and Summerell, 2006; Simmons, 1986).

\section{Pathogenicity test}

The pathogenicity test of the isolated fungi was done in desiccator under completely controlled conditions for which some farm soil was poured into Erlenmeyer flask and was sterilized in autoclave (twice, each time for 30 minutes) and then, some of this soil was put in sterile petri dishes. Afterwards, an amount of seeds of rice cv. Hashemi was disinfected in sodium hypochlorite solution $30 \%$ for one hour and then, 10 seeds were laid in soil in petri dishes. This was done in two desiccators, one as treatment and one as control. Two petri dishes were put in each desiccator. The petri dishes were poured with distilled water so that they were waterlogged during the experiment. Inoculation was done 16-18 days later when the seedlings in petri dishes were at two-leaf stage for which distilled water was first sprayed on all seedlings in control and treatment desiccator by hand sprayers (under sterile hood) and then, the spore suspension required for the inoculation was prepared (Safari Motlagh et al., 2005). In all experiments, a suspension containing $4 \times 10^{4}$ spores per $\mathrm{ml}$ distilled water was used which were counted by hemocytometer. In addition, Tween ${ }^{\circledR} 20$ with the ratio of $1 \%$ was used for improving surface absorption. It should be mentioned that desiccators were kept in incubator at $26^{\circ} \mathrm{C},>90 \%$ moisture, and 12/12 day/night light periods (Safari Motlagh et al., 2005). 


\section{Biological control studies}

\section{Inhibition of $B$. oryzae growth by culture filtrate}

The isolates of the studied fungi were cultured in 250-ml Erlenmeyer flasks containing potato dextrose broth (PDB) culture medium and they were shook at $26^{\circ} \mathrm{C}$ at $70 \mathrm{rpm}$ for 10 days. Then, they were extracted by biological filters and vacuum pump. Next, the extract was added to PDA culture medium. In control, the extract added to PDA culture medium lacked antagonistic fungus. A mycelial disc from 3-day culture of $B$. oryzaewas placed at the center of treatment and control petri dishes and then these petri dishes were transferred into incubator at $26^{\circ} \mathrm{C}$. After 10 days, radial growth of $B$. oryzae was calculated in control and treatment. Radial growth reduction was calculated by:

Percentage of inhibition of radial mycelial growth $=\frac{C-T}{C} \times 100$,

where $C$ is the radial growth of $B$. oryzae in control petri dishes and $T$ is its radial growth in the presence of other fungi (Dennis and Webster 1971a; Sivakumar et al., 2000).

\section{Slide culture technique (hyperparasitism test)}

A laboratorial slide was placed inside a $12-\mathrm{cm}$ petri dish on two L-shaped glass bars and was sterilized. Then, some of molten $2 \%$ water agar culture medium was poured on the slide as so a thin layer of agar was formed. Small mycelial discs of the desired antagonistic fungus and $B$. oryzae were placed on slide with $2-\mathrm{cm}$ spacing. A few milliliters of sterilized distilled water were added to each petri dish to avoid their drying. Petri dishes were kept at $26^{\circ} \mathrm{C}$. As soon as the mycelia of the fungi were reached to each other, the slides were studied under optical microscope (Sivakumar et al., 2000).

\section{The effect of volatile metabolites on inhibition of B. oryzae growth}

A mycelial disc with the diameter of $5 \mathrm{~mm}$ from the 3-day culture margin of $B$. oryzae was placed in the center of a petri dish containing PDA medium. Forty-eight hours later, a disc with the diameter of $5 \mathrm{~mm}$ from the 3-day culture of the studied fungi was placed in the center of another petri dish containing PDA. Then, the caps of these petri dishes were removed under sterile hood and the dish containing $B$. oryzae was placed upside-down on the petri dish containing the studied fungi. In control, the studied fungi were replaced by a disc from PDA medium. Inhibition percentage was calculated 10 days later (Dennis and Webster, 1971b; Sivakumar et al., 2000).

\section{Dual culture method}

A mycelial disc with the diameter of $5 \mathrm{~mm}$ taken from margins of 5-7-day culture of $B$. oryzae was placed under sterile hood in an 8-cm petri dish containing PDA with $2 \mathrm{~cm}$ spacing from the wall of petri dish. Then, the petri dish was placed in incubator at $26^{\circ} \mathrm{C}$ for 48 hours so that the fungus started its growth. Then, a mycelial disc with the diameter of $5 \mathrm{~mm}$ taken from the margins of 5-7-day fungus was placed at a distance of $3 \mathrm{~cm}$ from the pathogenic fungus. The petri dishes were placed at $26^{\circ} \mathrm{C}$ and the measurements were recorded 7-10 days later (Sivakumar et al., 2000). In disease controls, a mycelial disc from the 
margins of 5-7-day culture of B. oryzae was placed in the center of an 8-cm petri dish under sterile conditions. The control petri dishes were also placed in incubator at $26^{\circ} \mathrm{C}$. At the end of incubation, the radial growth of $B$. oryzae was measured in control and treatment. The reduction of radial growth comparison to control was calculated (Sivakumar et al., 2000).

\section{Data analysis}

The study was based on a randomized complete design with seven treatments and three replications. Data analysis was done using SAS software. In order to compare average values, least significant difference (LSD) method was used.

\section{RESULTS AND DISCUSSION}

The pathogenic nature of all Bipolaris spp. isolates was proved on rice and characteristics of these isolates as follows: grey to dark grey colonies grew and spread rapidly. Aerial mycelium was fluffy, cottony, grey olivaceous with brownish tinge. Conidiophores were single or in small groups, straight to flexuous, sometimes geniculate, pale to mid brown or olivaceous brown, pale towards the apex, septate $430-580 \times 4-7 \mu \mathrm{m}$ (average $500 \times 5 \mu \mathrm{m}$ ). Conidia were usually curved, navicular, fusoid or obclavate, occasionally almost cylindrical, pale to mid golden brown, smooth, 5-12 distoseptate, 46.5-125×10-26 $\mu \mathrm{m}$ and hilum was minute dark or light, often protruding, slightly papillate. The first septum was sub-median, the second delimited the basal cell and the third formed toward the apex of the conidium. Conidia germinated from polar cells and germ tube from the basal cell usually emerged immediately adjacent to the hilum and grows in the direction of the long axis (Figure 1). The general characteristics of this group are similar to Bipolaris Shoemaker, but special characteristics, such as shape and color of colony, morphology of conidium and conidiophore are similar to Bipolaris oryzae (Ito \& Kurib) Drechsler ex Dastur (Ellis, 1971; Sivanesan, 1987).

After preliminary identification of fungal isolates at genus level, 20 isolates that were not pathogenic on rice were selected for in vitro biological control studies and were further identified at species level. Accordingly, the following fungal groups were identified:

Characteristics of Group I: Colonies blackish brown with fast growth. Conidiophores simple or branched individually or in simple or branched groups, straight or curved groups, almost cylindrical, septate, light yellow or light brown, smooth, up to $115 \mu \mathrm{m}$ in length and $4.6 \mu \mathrm{m}$ in thickness. Conidia solitary or in short chains, straight or curved, obclavate or with the body of the conidium ellipsoidal tapering gradually to the beak which is up to half the length of the conidium, usually shorter, sometimes tapered to a point but more frequently swollen at the apex where there may be several scars, light yellow to golden brown, usually smooth, sometimes minutely verruculose, generally with 4-7 transverse and some longitudinal or oblique septa, slightly or not constricted at the septa, overall length: 22-95 $\mu \mathrm{m}$ (54), 8-19 $\mu \mathrm{m}$ thickness in the widest part, 2- 
$4 \mu \mathrm{m}$ at tip and 4-5 $\mu \mathrm{m}$ in the broadest part (Figure 2). Characteristics of this group of isolates were consistent with Alternaria tenuissima (Kunze) Wiltshire (Ellis, 1971).

Characteristics of Group II: Colonies effuse, olive green to black. Conidiophores simple or branched, straight or flexuous, septate, light brown to moderate or olive brown, up to $300 \mu \mathrm{m}$ in length, 3-5 $\mu \mathrm{m}$ in thickness, with terminal scar and sometimes with one or two lateral scars. Conidia solitary or simple or in 2-7 branched chains, straight to slightly curved with various shapes but generally obclavate or oval, mostly rostrate, light brown or moderate brown or sometimes dark or olive brown, smooth to verruculose with up to 8 traverse and numerous longitudinal or oblique septa, constricted at the septa, 8-60 (42) $\mu \mathrm{m}$ long, 6-24 (17) $\mu \mathrm{m}$ thickness in widest part (Figure 3). The characteristics of this group of isolates conformed to those of Alternaria citri (Ellis \& Pierce) (Ellis, 1971).

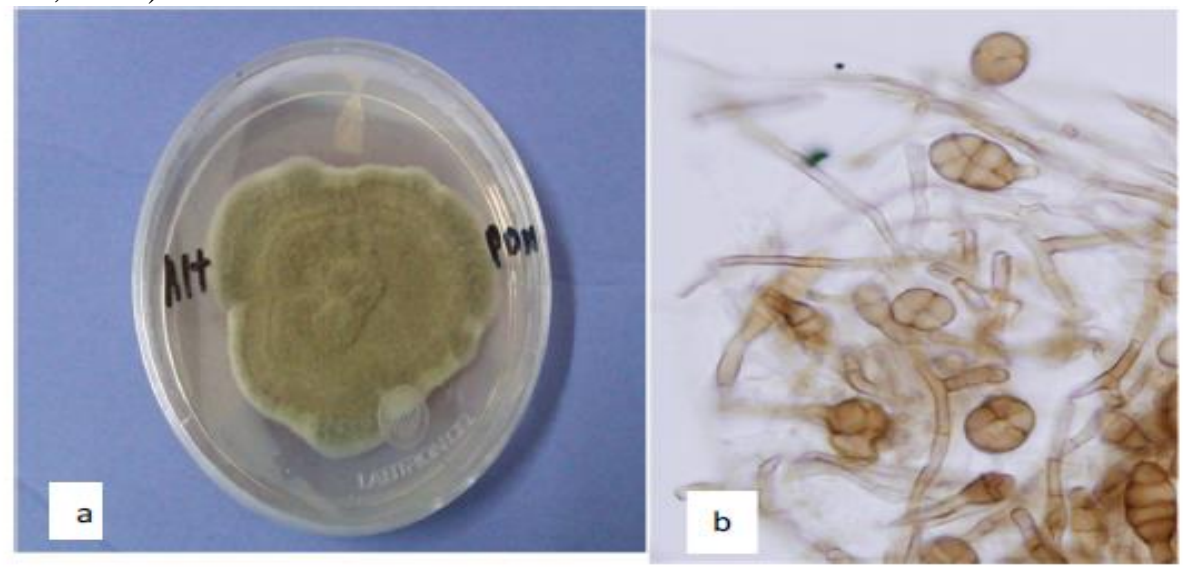

Figure 3. Alternaria citri: a) Colony on PDA, b) Conidia and conidiophores $(\times 1200)$

Characteristics of Group III: Colonies $5 \mathrm{~cm}$ diam, with 3-4 pairs of welldefined concentric circles of growth and sporulation. Colonies exhibited a series of strongly delimited, dark, concentric circles of dense sporulation concentrated near the substrate surface in light-exposed zones. These rings alternate with less dense zones of long, ascending and variously twisted aerial hyphae plus a few longer, trailing hyphae or hyphal ropes that wander over the aerial surface. The aerial texture appears openly wooly and slightly arachnoid. Conidiophores that sporulate in the surface mass commonly were unbranched but had 1-3 geniculate extensions and conidiogenous loci incorporated in a total length of 50-100 $\mu \mathrm{m}$. Each conidiogenous site produced a single conidium or more commonly a short chain or a branching chain of conidia, yielding a terminal cluster that was loose or crowded in density. The conidium population of a solitary, relatively small and open clump can be counted (at 50X) as 50-100. Clumps crowded within a surface ring were estimated to contain at least two or three times that number, with many comprising several thousand conidia. The architecture of an individual large head 
of sporulation derives from the primary plurigeniculate conidiophore; primary conidia at each geniculate site of the initial conidiophore, with each conidium generating its own apical, plurigeniculate secondary conidiophore of variable length; and enormous numbers of relatively small conidia in closely branching chains. The long hyphal elements that make up the open aerial layer of the colony may be simple or in funiculose ropes of 2-3 parallel hyphae, commonly 1 $\mathrm{mm}$ in length and 3-4 $\mu \mathrm{m}$ wide. They were variously twisted and curved, branching and intersecting, but each unit was distinct and can be traced visually through the layer. They produced scattered lateral conidiophores of variable length, each with a few conidia. Each of these long aerial axes also produced several branches near its tip. The largest conidia usually were primary and basal to a branching sporulation mass; each reached a size range of 35-40 $\times 7-9 \mu \mathrm{m}$, with up to 7 transverse septa and no longisepta, or with a single longiseptum in 14 of the transverse segments. The spore body of these conidia was narrowellipsoid or long-ovoid with a pyramidal apical cell. Usually the apical cell generated a secondary conidiophore of variable length, commonly 30-110 × 3-4 $\mu \mathrm{m}$ in size. Each secondary conidiophore had several geniculate extensions, commonly 4-6, with conidiogenous sites that generated branching chains of secondary conidia. Conidia of intermediate size were ellipsoid or narrow-ovoid, reach a size range of ca 15-30 $\times 5-7 \mu \mathrm{m}$, and had 3-5 transverse septa and no longisepta. These conidia were very abundant and were critical components in the elaboration of the branching system, in that each had a short apical secondary conidiophore with 1-3 geniculate extensions that generated terminal chains of spores. Conidia that constitute the terminal chains were produced in enormous numbers. They were ca 7-15 $\times$ 4-7 $\mu \mathrm{m}$ in size and had 0-3 transverse septa and usually no longisepta. The apical secondary conidiophore on each spore in a terminal chain was either a short single cell, a slight bulge differentiated in the apex of a conidium, or simply an apical perforation. Most conidia were almost smooth-walled and a medium, clear greenish brown. Largest conidia that were most advanced in septation may became slightly roughened and a darker brown at maturity (Figure 4). The characteristics of this group of isolates conformed to those of Alternaria infectoria E. G. Simmons (Simmons, 1986).

Characteristics of Group IV: Colonies on PDA medium attaining $80 \mathrm{~mm}$ diameter in $14 \mathrm{~d}$ at $23^{\circ} \mathrm{C}$. Texture cottony, adpressed and partially submerged, light brown to pink. Ascomata scattered to aggregated, developed superficially or partially immersed in culture media when young. Pseudothecia globose to spherical, smooth, almost glabrous, usually not ostiolate, light brown to dark brown. Ascomata ornamentation consisting on septate and flexuose hyphae, 5-10 $\times 2-2.5 \mu \mathrm{m}$. Asci $80-110 \times 10-13 \mu \mathrm{m}$, eight spored, cylindrical to clavate, broadly rounded above and gradually to abruptly tapering into a robust stipe of $10 \times 5$ $\mu \mathrm{m}$. Pseudoparaphyses $10-15 \mu \mathrm{m}$, filiform, septate and longer than the asci, mixed with them and bifurcate. Ascospores 32-47 $\times 6-10 \mu \mathrm{m}$, two-celled, cells easily separable at the central septum, cylindrical, hyaline to olivaceous. When young and finally becoming olivaceous brown to dark brown when mature; 
transversely septate, constrictions at septa broad and shallow, middle cells of equal length and broader than terminal cells, provided with rounded apices; germ slit diagonal, oblique or parallel and straight to sinuous; gelatinous sheath hyaline and narrow, less than $4 \mu \mathrm{m}$ wide (Figure 5). The characteristics of this group corresponded with Preussia sp. Fuckel (Cain, 1961; Arenal et al., 2004; Arenal et al., 2007).
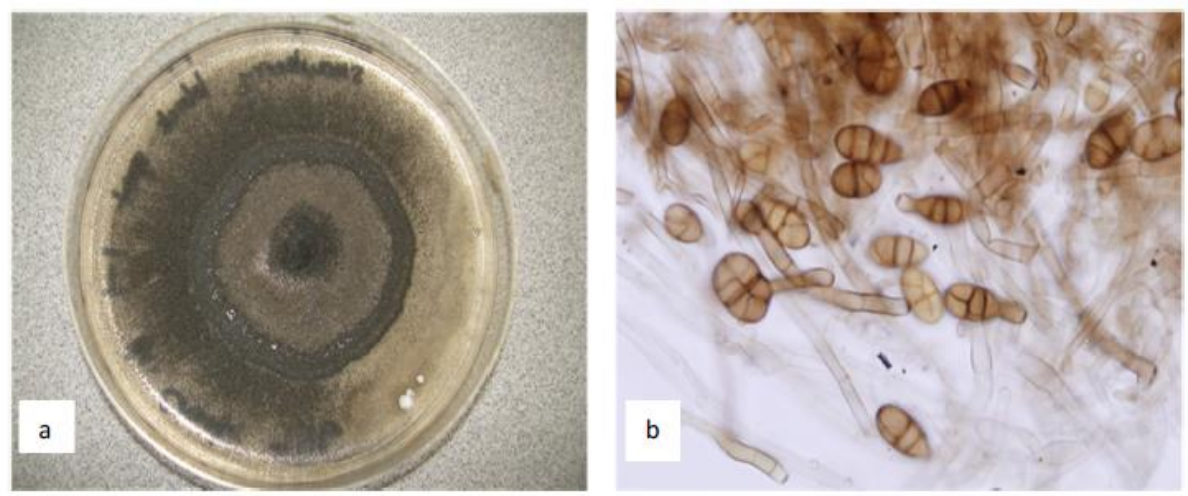

Figure 4. Alternaria infectoria: a) Colony on PDA, b) Conidia and conidiophores $(\times 1200)$
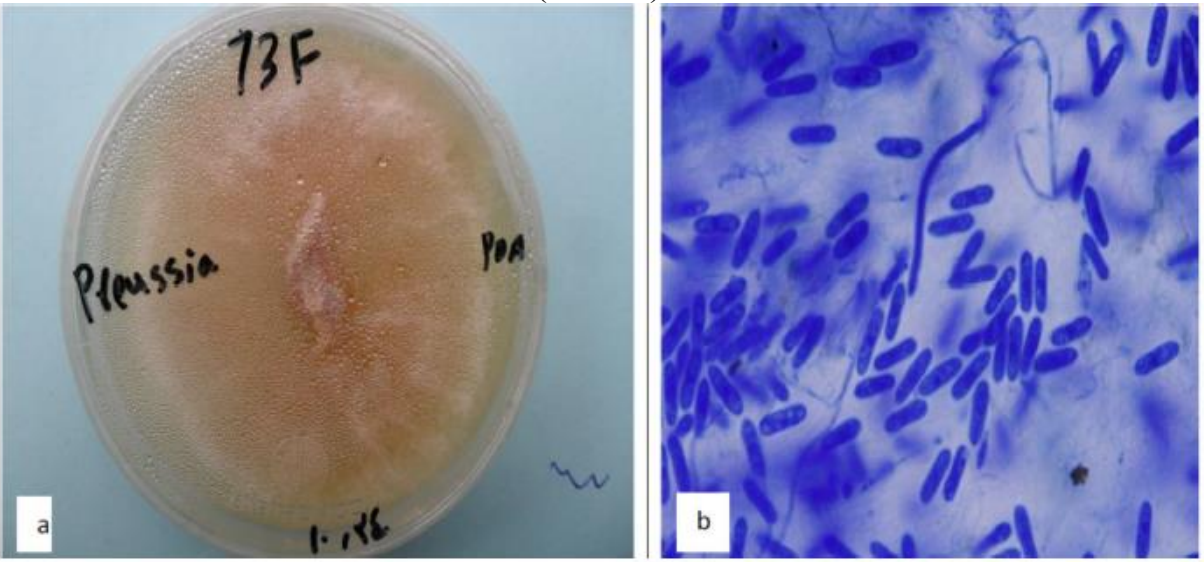

Figure 5. Preussia sp.: a) Colony on PDA, b) Ascospores (× 1200)

Characteristics of Group V: Initially cultures had white mycelia but occasionally developed violet pigments with age. Blue-black sclerotia developed in some isolates. Macroconidia relatively long and slender, slightly falcate or straight and thin walled. Apical cell curved and often tapered to a point, basal cell notched or foot shaped and 3-5 septa. Microconidia oval to club shaped with a flattened base and usually without septa. Conidiogenous cells monophialidic which were occasionally produced in pairs. Chlamydospores were not produced (Figure 6). The characteristics of this group of isolates conformed to those of Fusarium verticillioides (Saccardo) Nirenberg (Leslie and Summerell, 2006). 


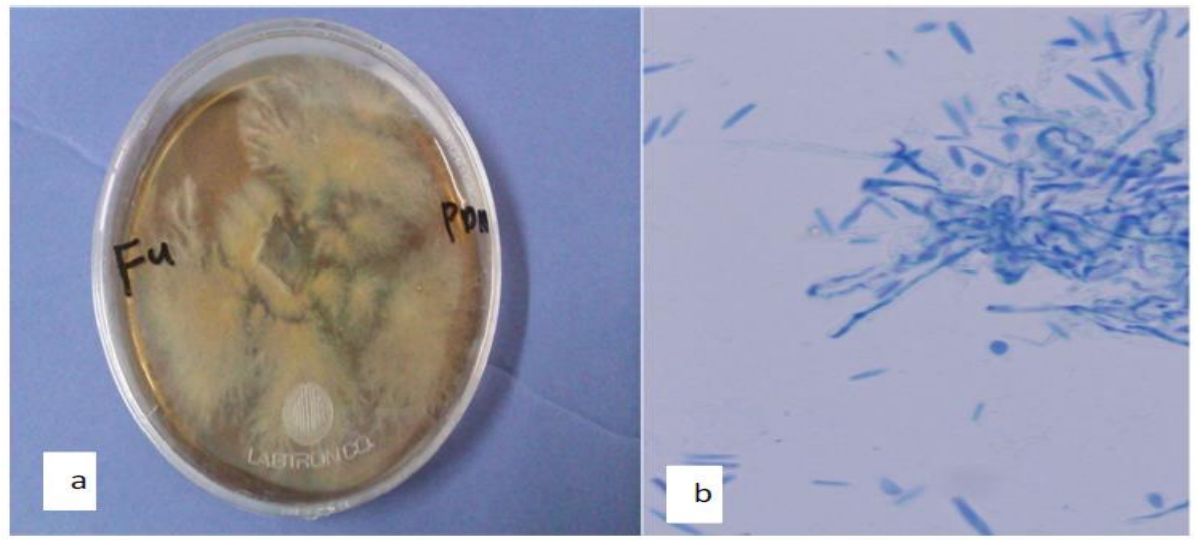

Figure 6. Fusarium verticillioides: a) Colony on PDA, b) Conidia $(\times 1200)$

Characteristics of Group VI: Colonies growing rapidly (most isolates 7-9 $\mathrm{cm}$ ). Conidiation predominantly effuse, appearing granular or powdery due to dense conidiation; rapidly turning yellowish-green to dark green, or producing tufts or pustules fringed by sterile white mycelium. Reverse colourless to dull yellowish, buff or drab. Odour indistinct or faintly earthy. Conidiophores as in the section, tending to be regularly verticillate forming a pyramidal structure. Phialides ampulliform to lageniform, usually 3-4-verticillate, occasionally paired, mostly $3.5-7.5 \times 2.5-3.8 \mu \mathrm{m}$, terminal phialides up to $10 \mu \mathrm{m}$ long. Conidia subglobose to obovoid, mostly (2.5-) 2.7-3.5 × 2.1-2.6 (-3.0) $\mu \mathrm{m}$, smooth-walled, subhyaline to pale green (Figure 7). The characteristics of this group corresponded with Trichoderma harzianum Rifai (Gams and Bissett, 1998).
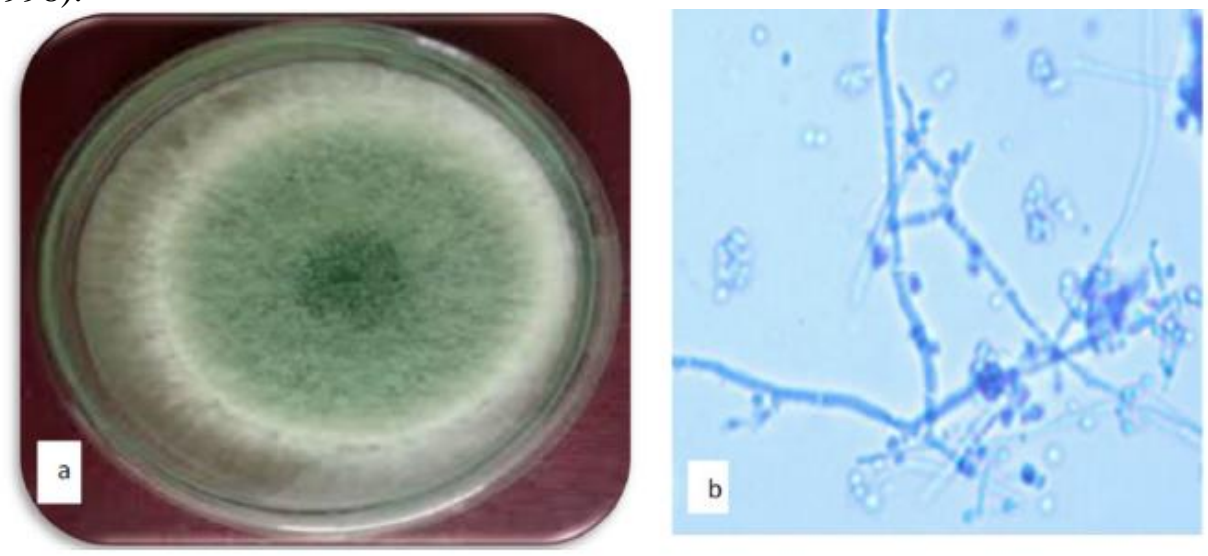

Figure 7. Trichoderma harzianum: a) Colony on PDA, b) Conidia and conidiophores $(\times 1200)$

Characteristics of Group VII: Colonies growing rapidly $(6-7 \mathrm{~cm})$. Conidiation mostly predominantly effuse, covering the entire surface of the plate, or forming spreading, flat pustules concentrated near the margin of the plate or 
arranged concentrically; quickly turning dark bluishgreen. Reverse colourless, or slowly developing dull yellowish to amber shades. Odour indistinct. Conidiophores in areas of effuse conidiation arising as lateral branches from undifferentiated aerial mycelium, at the base frequently sterile and unbranched for about half the length, toward the apex branching irregularly with each branch terminated by a cluster of 3-6 closely appressed phialides; macronematous conidiophores branching irregularly, the upper part fertile to the apex and the apex frequently bearing a terminal whorl of appressed branches and phialides; primary branches usually arising singly or in opposite pairs immediately beneath septa, the entire branching system irregular and uncrowded. Phialides from complex conidiophores lageniform to ampulliform, mostly 4.5-10 $(-13) \times 2.8$ $5.5 \mu \mathrm{m}$, mostly arising in closely appressed verticils of $2-5$ on terminal branches, occasionally solitary or in pairs laterally on the conidiophore and branches; phialides from effuse areas of conidiation lageniform to subulate, up to $20 \mu \mathrm{m}$ long $\times 2.5-3 \mu \mathrm{m}$. Conidia broadly ellipsoidal to obovoid, mostly $3.5-6.0 \times 2.8-$ $4.1 \mu \mathrm{m}$, smooth-walled, dark green, conidia from adjacent phialides often coalescing into large gloeoid masses (Figure 8). The characteristics of this group corresponded with Trichoderma virens (J. Miller, Giddens \& Foster) von Arx, Beih (Gams and Bissett, 1998).
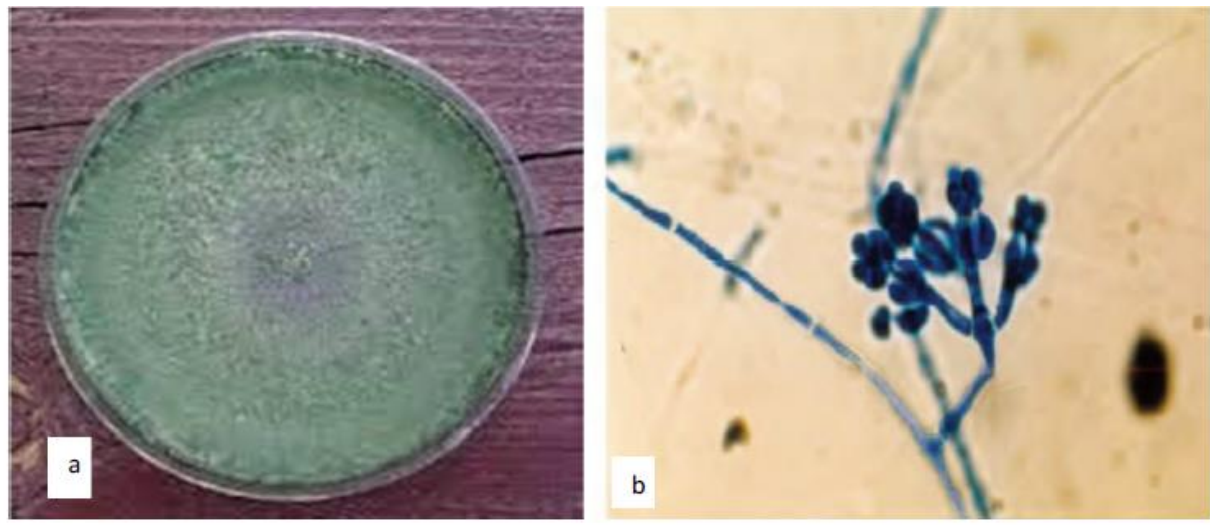

Figure 8. Trichoderma virens: a) Colony on PDA, b) Conidia and conidiophores $(\times 1200)$

In evaluation of inhibition of B. oryzae growth by culture filtrate, it was found that T. harzianum had the highest inhibitory effect of $66.79 \%$ on the growth of B. oryzae colony. The isolates of T. virens, A. tenuissima, Preussia sp., F. verticillioides, A. infectoria and A. citri had the next highest efficiencies in reducing the growth of colony of $\mathrm{B}$. oryzae (Table 1). Analysis of variance of the growth inhibition showed significant differences among the studied fungi at the $1 \%$ probability level. 
Table 1. Comparison of means of growth inhibition by Least Significant Difference (LSD) in culture filtrate method

\begin{tabular}{|c|c|}
\hline Fungal isolates & Growth inhibition (\%) \\
\hline F. verticillioides & $43.37 \mathrm{bc}$ \\
\hline A. tenuissima & $51.34 \mathrm{~b}$ \\
\hline T. harzianum & $66.79 \mathrm{a}$ \\
\hline T. virens & $65.72 \mathrm{a}$ \\
\hline A. citri & $41.39 \mathrm{c}$ \\
\hline A. infectoria & $43.13 \mathrm{bc}$ \\
\hline Preussia sp. & $47.51 \mathrm{bc}$ \\
\hline LSD 5\% & 9.562 \\
\hline
\end{tabular}

Treatments having at least one similar letter do not show a significant difference at $\mathrm{P}=0.05$.

In evaluation of hyperparasitism test, the hyphae of $T$. harzianum and $T$. virens did not coil around the mycelium of the fungal agent of rice brown spot disease. The hyphae isolates of Preussia sp. and $F$. verticillioides penetrated into the mycelium of $B$. oryzae, but were not able to deform them. The hyphae of $A$. tenuissima, $A$. infectoria and $A$. citri penetrated into the mycelium of $B$. oryzae once they reached them and then, they tore the fungal mycelium and deformed them.

In evaluation of inhibitory effect of volatile metabolites on $B$. oryzae growth, $T$. harzianum had the highest inhibitory effect of $83.13 \%$ on mycelial growth of $B$. oryzae. The next highest inhibitory effect on reducing mycelial growth of brown spot fungus was exerted by the isolates of $T$. virens, $A$. tenuissima, A. infectoria, A. citri, Preussia sp. and $F$. verticillioides, respectively (Table 2).

Table 3. Comparison of means of growth inhibition by Least Significant Difference (LSD) in dual culture method

\begin{tabular}{|c|c|}
\hline Fungal isolates & Growth inhibition (\%) \\
\hline F. verticillioides & $34.63 \mathrm{bc}$ \\
\hline A. tenuissima & $41.99 \mathrm{~b}$ \\
\hline T. harzianum & $52.87 \mathrm{a}$ \\
\hline T. virens & $51.63 \mathrm{a}$ \\
\hline A. citri & $32.63 \mathrm{c}$ \\
\hline A. infectoria & $34.57 \mathrm{bc}$ \\
\hline Preussia sp. & $38.23 \mathrm{bc}$ \\
\hline LSD 5\% & 8.058 \\
\hline
\end{tabular}

Treatments having at least one similar letter do not show a significant difference at $\mathrm{P}=0.05$.

According to the analysis of variance of inhibition percentage in this method, the treatments showed significant differences at the $1 \%$ probability level. It was revealed that fungi had significant differences in inhibition percentage.

In evaluation of dual culture method, the growth of $B$. oryzae in the absence of $F$. verticillioides averaged $60.1 \mathrm{~mm}$ (in control), whilst the growth of these isolates in the presence of $F$. verticillioides averaged $39.29 \mathrm{~mm}$ implying 
that $F$. verticillioides suppressed the mycelial growth of $B$. oryzae isolates. The suppression percentage of $B$. oryzae growth by $F$. verticillioides was $34.63 \%$ (Figure 9).

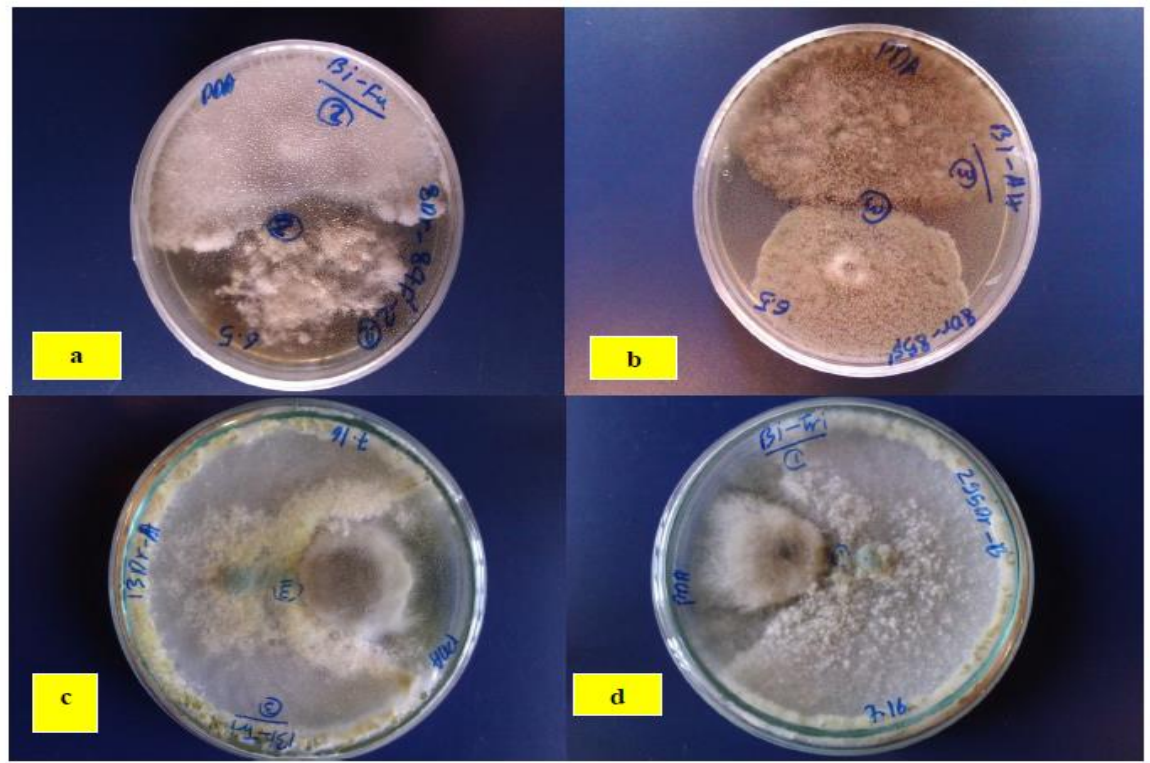

Figure 9. Dual culture method: a) B. oryzae $\times F$. verticillioides, b) $B$. oryzae $\times A$. tenuissima, c) B. oryzae $\times$ T. harzianum, d) B. oryzae $\times T$. virens

Mean growth of $B$. oryzae isolates was $60.77 \mathrm{~mm}$ in the absence of $A$. tenuissima (in controls), whilst mean growth of these isolates was $35.26 \mathrm{~mm}$ in the presence of $A$. tenuissima. It shows that $A$. tenuissima stunted the mycelial growth of $B$. oryzae isolates by $41.99 \%$ (Figure 9 ).

The growth of $B$. oryzae isolates averaged $60.82 \mathrm{~mm}$ in the absence of $T$. harzianum antagonist (in controls) whilst it was $28.66 \mathrm{~mm}$ in the presence of $T$. harzianum implying the role of $T$. harzianum in inhibiting the mycelial growth of Bipolaris spp. isolates by $52.87 \%$ (Figure 9).

Mean growth of $B$. oryzae isolates was $60.8 \mathrm{~mm}$ (in controls) in the absence of $T$. virens and $29.41 \mathrm{~mm}$ in its presence. It concludes that $T$. virens inhibited the mycelial growth of $B$. oryzae isolates by $51.63 \%$ (Figure 9 ).

$B$. oryzae isolates grew up to $65.31 \mathrm{~mm}$ in the absence of $A$. citri (in controls), while they reached $44 \mathrm{~mm}$ in the presence of $A$. citri implying that $A$. citri hindered the mycelial growth of $B$. oryzae isolates by $32.63 \%$ (Figure 10).

The growth of $B$. oryzae isolates averaged $65.3 \mathrm{~mm}$ (in controls) in the absence of $A$. infectoria, whereas it was $42.72 \mathrm{~mm}$ in the presence of this fungus. It reveals that $A$. infectoria inhibited the mycelial growth of $B$. oryzae isolates by $34.57 \%$ (Figure 10). Mean growth of B. oryzae isolates was $75 \mathrm{~mm}$ (in controls) in the absence of Preussia sp. and $46.33 \mathrm{~mm}$ in its presence. It concludes that Preussia sp. inhibited the mycelial growth of $B$. oryzae isolates by $38.23 \%$ (Figure 10). 


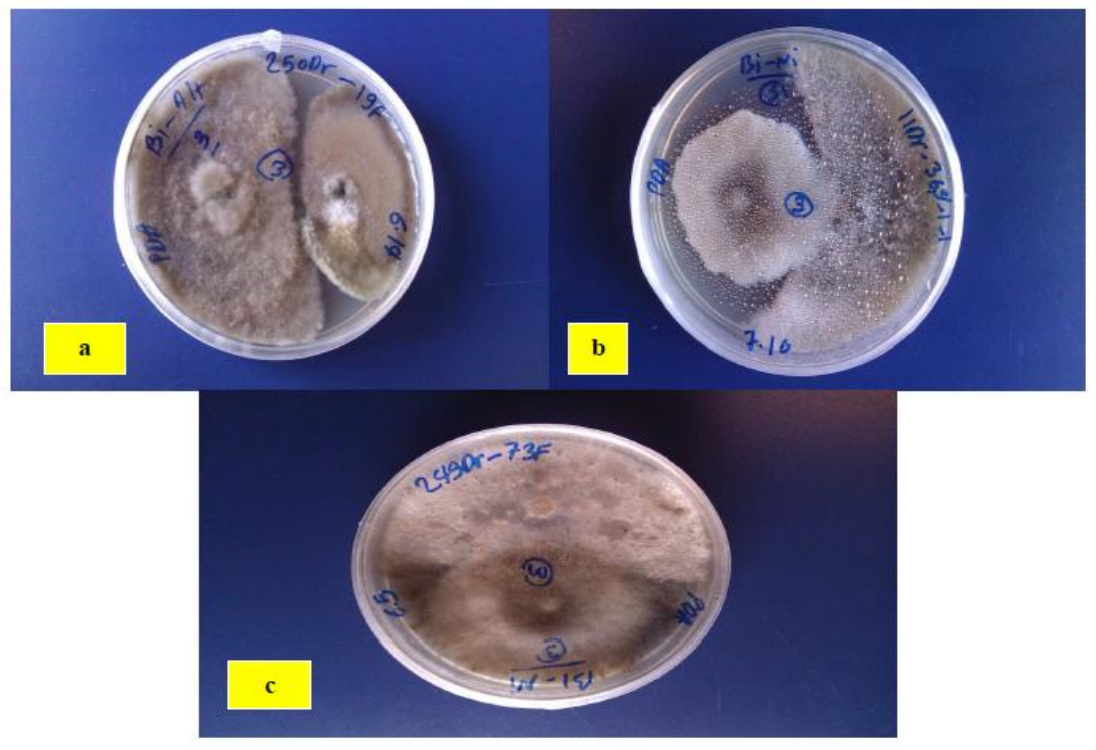

Figure 10. Dual culture method: a) B. oryzae $\times$ A. citri, b) B. oryzae $\times A$. infectoria, c) B. oryzae $\times$ Preussia $\mathrm{sp}$.

Inhibition percentage was calculated according to the results of dual culture, and out of 20 isolates used in dual culture, seven isolates suppress the growth of $B$. oryzae isolates more than others: $F$. verticillioides, A. tenuissima, $T$. harzianum, T.virens, A. citri, A. infectoria and Preussia sp. Following T. harzianum which had the highest inhibition percentage for $B$. oryzae, the isolates of T. virens, A. tenuissima, Preussia sp., F. verticillioides, A. infectoria and A. citri had the highest suppression percentage, respectively. Analysis of variance of inhibition percentage in dual culture showed significant differences among fungi at the $1 \%$ probability level (Table 4). Means comparison for inhibition percentage by least significant differences (LSD) method led to these results: the highest suppression percentage was related to treatments 3 and 4, i.e. control with $T$. harzianum and $T$. virens, which exhibited significant differences with treatments 1,2, 5, 6 and 7 and the lowest suppression percentage was related to treatment 5, i.e. control with $A$. citri which had no significant differences with treatments 1, 6 and 7 (F. verticillioides, A. infectoria and Preussia sp.) (Table 3). Therefore, controlling with $T$. harzianum and $T$. virens showed the best efficiency among all studied fungi.

In the present study, Bipolaris spp., Alternaria spp., Nigrospora spp., Fusarium spp., Trichoderma spp. and Preussia sp. and some saprophytic fungi were isolated from rice from paddy fields of Guilan province. After elementary identification at genus level, 68 isolates were used for pathogenic studies and their pathogenicity of all isolates of Bipolaris spp. (34 isolates) was proved on rice. Alternaria citri which is pathogenic on citrus and also, Preussia sp. were among the fungi that were isolated from rice and were reported for the first time on rice from Iran. 
Table 4. Variance analysis of inhibition mycelial growth

\begin{tabular}{|c|c|c|}
\hline SOV & DF & MS \\
\hline Treatment & 6 & $207.191^{* *}$ \\
\hline Error & 14 & 20.518 \\
\hline C.V. & - & 11.064 \\
\hline
\end{tabular}

$* *$ Significance of the probability level of $1 \%$

SOV: sources of variations; DF: degree of freedom; MS: squares mean

Among fungal isolates used in vitro, seven isolates including Fusarium verticillioides, Alternaria tenuissima, Trichoderma harzianum, Trichoderma virens, Alternaria citri, Alternaria infectoria and Preussia sp. suppressed mycelial growth of Bipolaris oryzae more efficiently than other isolates. In dual culture and culture filtrate methods, the isolates of T. harzianum, T. virens, A. tenuissima, Preussia sp., F. verticillioides, A. infectoria and $A$. citri inhibited the mycelial growth of $B$. oryzae more than other isolates, respectively but in volatile metabolites method, the most effective isolates in inhibition were respectively: $T$. harzianum, T. virens, A. tenuissima, A. infectoria, A. citri, Preussia sp. and F. verticillioides.

The isolates applied in these methods were all more efficient in volatile metabolites method in biological control of rice brown spot disease.

$T$. harzianum suppressed the growth of B. oryzae isolates by $52.87-83.13 \%$ in vitro and found to be the most effective isolate which was in agreement with Khalili et al. (2012) who stated that Trichoderma spp. isolates considerably inhibited the in vitro mycelial growth of $B$. oryzae and also was in agreement with Abdel-Fattah et al. (2007) who stated that T. harzianum antifungal metabolites suppressed the linear growth of B. oryzae.

$T$. virens isolates suppressed the in vitro mycelial growth of $B$. oryzae by 51.63-76.41\%. It was consistent with Ru and Di (2012) and Khalili et al. (2012) who found that $T$. virens had a good influence on biological control of potato dry rot and rice brown spot diseases, respectively.

In another study, the biological control effect of Alternaria infectoria against Ceroplastes rusci as a plant pest was examined and it was evaluated as to be effective on the biological control of this pest (Shabana and Ragab, 1997).

Naeimi et al. (2011) studied antagonistic effect of Trichoderma strains on $R$. solani. In vitro Trichoderma strains effectively reduced the growth of $R$. solani. Some strains inhibited the production of $R$. solani sclerotia in vitro and in field conditions and suppressed the germination and growth of developed sclerotia. Seven Trichoderma strains that were shown in greenhouse assessments to have the highest effect were antagonist in dual culture too. In contrast, no relationship was found between their in vitro biological control activities and their usefulness in the control of rice sheath blight in greenhouse. For instance, $T$. harzianum AS12-2 did not hinder the in vitro formation of sclerotia, but was the most effective isolate in the control of rice sheath blight in greenhouse. The spray 
of these antagonists' spores on rice plants infected by $R$. solani provided an effective transferring system for the control of this disease.

Akrami et al. (2011) examined the effect of Trichoderma spp. isolates on Fusarium sp. The results of dual culture revealed that medium was soon colonized with Trichoderma isolates and that all evaluated Trichoderma isolates were effective in the control of Fusarium isolates. As well, the assessment of the production of volatile and non-volatile substances showed promising performance in the suppression of pathogenic mycelial growth. They, also, stated that $T$. vierns was very effective in the control of Fusarium sp. at $35^{\circ} \mathrm{C}$ in damp soil and three isolates, T. harzianum, T. asperellum, and T. virens, were effective against lentil Fusarium rot.

In a study, it was indicated that rice inoculation with spore suspension of Trichoderma isolates reduced the germination of $B$. oryzae spores on plant significantly (Tsahouridou and Thanassoulopoulosh, 2002).

Khalili et al. (2012) studied antagonistic activity of T. harzianum against Bipolaris oryzae. In vitro tests showed that local isolates of Trichoderma sp. significantly suppressed the mycelial growth of $B$. oryzae. According to the results, there was clearly a competition between $T$. harzianum and $B$. oryzae. Trichoderma isolates grow faster and outperform the pathogenic fungus in the competition for space and nutrients resulting in the inhibition of the growth of the target organism. Microscopic observations showed no mycoparasitism between Trichoderma and $B$. oryzae isolates that was in agreement with present study.

In a study on the antagonistic effect of seven isolates including $F$. verticillioides, A. tenuissima, T. harzianum, T. virens, A. citri, A. infectoria and Preussia sp. on the mycelial growth of $B$. victoriae in laboratorial and greenhouse conditions, it was revealed that $T$. harzianum was the most effective antagonist in suppressing the mycelial growth of $B$. oryzae under laboratorial conditions and Preussia sp. and T. harzianum were the most effective isolates on reducing the intensity of brown spot disease under greenhouse conditions (Mohammadian, 2013) which was consistent with our findings in the present study in vitro.

\section{CONCLUSIONS}

Biological control is one of the best control methods against some plant pathogens. This strategy of control is ecologically clean and compatible with different models of agriculture organic biological and pathogen management.

This study indicated that $T$. harzianum, $T$. virens and A. tenuissima were the most effective fungal isolates in biological control of rice brown spot disease agent. So, they can be introduced as antagonistic fungi.

The study revealed that there are some fungi in natural rice flora that have potential antagonism for biological control of the causal fungus of rice brown spot disease. The identification and examination of these fungi in vitro, greenhouse and paddy fields levels can be promising about the efficiency of biological control in the management of rice brown spot disease. 


\section{ACKNOWLEDGMENT}

This experiment was supported by the Islamic Azad University, Rasht Branch, Iran.

\section{REFERENCES}

Abdel-Fattah, G. M., Shabana, Y. M., Ismail, A. E. \& Rashad, Y. M. (2007). Trichoderma harzianum: a biocontrol agent against Bipolaris oryzae. Mycopathologia, 164 (2), 81-89.

Akrami, M., Golzary, H. \& Ahmadzadeh, M. (2011). Evaluation of different combinations of Trichoderma species for controlling Fusarium rot of lentil. African Journal of Biotechnology, 10(14): 2653-2658.

Arenal, F., Platas, G. \& Peláez, F. (2004). Variability of spore length in some species of the genus Preussia (Sporormiella). Mycotaxon, 89: 137-151.

Arenal, F., Platas, G. \& Pelaez, F. (2007). A new endophytic species of Preussia (Sporomiaceae) inferred from morphological observations and molecular phylogenetic analysis. Fungal Diversity, 25:1-17.

Cain, R.F. (1961). Studies of coprophilous ascomycetes. VII. Preussia. Canadian Journal of Botany, 39: 1633-1666.

Carissimi, M., Giraudo, M. S., Germani, J. C. \& Van Der Sand, S. T. (2009). Antifungal activity of Bacillus sp. E164 against Bipolaris sorokiniana. Biociencias, 17(1):48-58.

Dennis, C. \& Webster, J. (1971a). Antagonistic properties of species-groups of Trichoderma. I. Production of nonvolatile antibiotics. Transactions of the British Mycological Society, 57(1): 25-39.

Dennis, C. \& Webster, J. (1971b). Antagonistic properties of species-groups of Trichoderma. II. Production of volatile antibiotics. Transactions of the British Mycological Society, 57(1): 4148.

Elad, Y., Chet, I. \& Katan, J. (1980). Trichoderma harzianum: A biocontrol agent effective against Sclerotium rolfsii and Rhizoctonia solani. Phytopathology, 70:119-121.

Ellis, M. B. (1971). Dematiaceous Hyphomycetes. CMI, Kew, England.

Gams, W. \& Bissett, J. (1998). Morphology and identification of Trichoderma. In: Kubicek, C. P., Harman, G. E., (eds). Trichoderma and Gliocladium. Vol. 1. Basic Biology, Taxonomy and Genetics, Taylor and Francis Ltd., London: 3-34.

Howell, C. R. (1982). Effect of Gliocladium virens on Pythium ultimum, Rhizoctonia solani and damping-off of cotton seedlings. Phytopathology, 72:496-498.

Kazemzadeh Chekosari, M. (2003). A feasibility study on biological control of rice sheat blight disease (Rhizoctonia solani) by some bacterial biocontrol agents. Tehran University, Abureyhan Higher Education Institution (M.Sc. thesis). (in Persian with English abstract).

Khalili, E., Sadravi, M., Naeimi, Sh. \& Khosravi, V. (2012). Biological control of rice brown spot with native isolates of three Trichoderma species. Brazilian Journal of Microbiology, 43 (1): 297-305.

Khodaparast, S. A. \& Sahragard, A. (2004). Rice diseases. The University of Guilan Press. (in Persian).

Leslie, J. F. \& Summerell, B. A. (2006). The Fusarium, laboratory manual. Blackwell Publishing.

Lewis, J. A. \& Papavizas, G. C. (1991). Biocontrol of cotton damping-off caused by Rhizoctonia solani in the field with formulations of Trichoderma spp. and Gliocladium virens. Crop Protection, 10:396-402.

Manimegalai, V., Ambikapathy, V. \& Panneerselvam, A. (2011). Biological control of paddy brown spot caused by Bipolaris oryzae. European Journal of Experimental Biology, 1 (4):2428.

McSpadden, G. B. B. \& Fravel, D. R. (2002). Biological control of plant pathogens, Research commercialization and application in the USA. Plant Health Progress, 10.1094/PHP-20020510-01-RV.

Mohammadian, S. (2013). Biological control of Bipolaris spp., the causal agent of brown spot disease of rice by some antagonistic fungi in Guilan province. Islamic Azad University, Science and Research Branch, Guilan, Rasht (M.Sc. thesis). (in Persian with English abstract).

Mpika, J., Kébé, I. B., Issali, A. E., N'Guessan, F. K., Druzhinina, S., Komon-Zélazowska, M., Kubicek, C. P. \& Aké, S. (2009). Antagonist potential of Trichoderma indigenous isolates for 
biological control of Phytophthora palmivora, the causative agent of black pod disease on cocoa (Theobroma cacao L.) in Côte d'Ivoire. African Journal of Biotechnology, 8(20):52805293.

Moura, A. T., Ludwig, J., Santos, A. G., Schafer, J. T., Soares, V. N. \& Correa, B. O. (2014). Biocontrol and seed transmission of Bipolaris oryzae and Gerlachia oryzae to rice seedlings. Journal of Seed Science, 36(9): 407-412.

Naeimi, Sh., Okhovvat, S. M., Javan-Nikkhah, M., Vágvölgyi, C., Khosravi, V. \& Kredicks, L. (2011). Biological control of Rhizoctonia solani AG1-1A, the causal agent of rice sheath blight with Trichoderma strains. Phytopathologia Mediterranea, 49 (3):287-300.

Nazari, S., Javan Nikkhah, M., Khalil-Berdi, F., Khosravi, V. \& Alizadeh, A. (2015). Bipolaris species associated with rice plant: pathogenicity and genetic diversity of Bipolaris oryzae using rep-PCR in Mazandaran province of Iran. Journal of Crop Protection, 4 (4): 497-508.

Niknejad, M. \& Sharifi Tehrani, A. (1993). A study on antagonistic effect of Trichoderma on the causal agent of tomato fusarium wilting disease, Fusarium oxysporum f. sp. lycopersici in vitro and in greenhouse. $11^{\text {th }}$ Iranian Congress of Plant Protection, 27 Augest - 1 September, Rasht, pp. 165. (in Persian with English abstract).

Ningthoujam, D. S., Sanasam, S., Tamreihao, K. \& Nimaichand, S. (2009). Antagonistic activities of local actinomycetes isolates against rice fungal pathogen. African Journal of Microbiology Research, 3(11):737-742.

Ou, S. H. (1985). Rice diseases. Commonwealth Mycological Institute, 2nd ed.

Ru, Z., Di, W. (2012). Trichoderma spp. from rhizosphere soil and their antagonism against Fusarium sabbucinum. African Journal of Biotechnology, 11(18):4180-4186.

Safari Motlagh, M. R. (2010). Isolation and characterization of some important fungi from Echinochloa spp., the potential agents to control rice weeds. Australian Journal of Crop Science, 4(6):457-460.

Safari Motlagh, M. R. (2000). Etiology of rice brown spot disease in Guilan province. Tehran University (M.Sc. thesis). (in Persian with English abstract).

Safari Motlagh, M. R., Padasht Dehkaee, F. \& Hedjaroud, G.A. (2005). Rice brown spot disease and evaluation of the response of some rice cultivars to it. Journal of Science and Technology of Agriculture and Natural Resources, 9(2): 171-182. (in Persian with English abstract).

Salehpour, M., Etebarian, H. R., Roustaei, A., Khodakaramian, G. \& Aminian, H. (2005). Biological control of common root rot of wheat (Bipolaris sorokiniana) by Trichoderma isolates. Plant Pathology Journal, 4(1): 85-90.

Shabana, Y. M. \& Ragab, M. E. (1997). Alternaria infectoria, a promising biological control agent for the Fig Wax Scale, Ceroplastes rusci (Homoptera: Coccidae), in Egypt. Biocontrol Science and Technology, 7:553-564.

Simmons, E. G. (1986). Alternaria themes and variations (22-26). Mycotaxon, 25(1):287-308.

Sivakumar, D., Wilson Wijeratnam, R. S., Wijesundera, R. L. C., Marikar, F. M. T. \& Abeyesekere, M. (2000). Antagonistic effect of Trichoderma harzianum on postharvest pathogens of Rambutan (Nephelium lappaceum). Phytoparasitica, 28 (3):240-247.

Sivanesan, A. (1987). Gramainicolous species of Bipolaris, Curvularia, Drechslera, Exserohilum and their telemorphs. CAB International Mycological Institute.

Soltani Nejad, M., Shahidi Bonjar, G. H. \& Padasht Dehkaei, F. (2014). Control of Bipolaris oryzae the causal agent of rice brown spot disease by soil Streptomyces sp. isolate G. International Journal of Advanced Biological and Biomedical Research, 4(2): 310-317.

Srivastava, R. \& Shalini, R. S. (2008). Antifungal activity of Pseudomonas fluorescens against different plant pathogenic fungi. Journal of Environmental, Agricultural and Food Chemistry, 7(4):2789-2796.

Tsahouridou, P.C. \& Thanassoulopoulosh, C. C. (2002). Proliferation of Trichoderma koningii in the tomato rhizosphere and the suppression of damping off by Sclerotium rolfsii. Soil Biology \& Biochemistry, 34:767-776.

Zhang, Z. \& Yuen, G. Y. (2000). The role of chitinase production by Stenotrophomonas maltophilia strain C3 in biological control of Bipolaris sorokiniana. Phytopathology, 90:384389. 